\title{
El proceso de descentralización en América Latina: Balance y perspectivas ${ }^{1}$
}

\section{The decentralization process in Latin America: balance and perspectives}

DOI: http://dx.doi.org/10.17981/econcuc.38.2.2017.01

Recibido: abr 19/2017 Devuelto para revisión: may 18/17 Aceptado: jul 19/2017

Ángela Aponte Pinzón ${ }^{2}$

\begin{abstract}
Resumen
Este artículo de revisión estudia la descentralización latinoamericana como un proceso gradual con base en reformas del Consenso de Washington, cuya base teórica es la escuela neoinstitucional, en la cual se percibía al Estado como el garante de reglas que garantizaran el normal funcionamiento de las fases económicas. Estas políticas tenían varios fines: apertura económica, privatización, creación de instituciones independientes, descentralización. Asimismo, cada país desarrolló el proceso de manera diferente: en algunos existió dependencia de transferencias nacionales, otros accedieron al endeudamiento sin mostrar crecimiento; sin embargo, otras naciones aprovecharon el proceso incrementando sus ingresos propios, reflejando que las reformas podían generar beneficios.
\end{abstract}

Palabras clave: descentralización; instituciones; transferencias directas; Consenso de Washington; ingresos propios.

\begin{abstract}
This review article studies the Latin-America decentralization as a gradual process base on reforms of the Washington Consensus, which theoretical base is the Neo-institutional School, where the State was seen as the guarantor of the rules that guarantee the economic phases normal functioning. These policies had several goals: economic openness, foundation of independent institutions, decentralization, but each country developed this process in a different way: in some of them there existed a dependence on national transactions, some others agreed to debt without experimenting any growth; however, some nations took advantage of the process by increasing their own income, reflecting that the reforms could generated benefits.
\end{abstract}

Keywords: Decentralization; institutions; direct transfers; Washington consensus; own income.

\footnotetext{
${ }^{1}$ Artículo científico como resultado del proyecto de investigación: Análisis del proceso de descentralización: Una mirada al esfuerzo fiscal en los municipios de sexta categoría del departamento de Boyacá, durante el período 1993-2012.

${ }^{2}$ Estudiante de Maestría en Economía en la Universidad Pedagógica y Tecnológica de Colombia - UPTC, Tunja. Correo: angeappi30@hotmail.com
} 


\section{Introducción}

Las finanzas públicas en América Latina, desde la década de los 90, han sufrido grandes transformaciones de tipo político, social, económico e institucional debido a la implementación de las políticas del Consenso de Washington y como respuesta a la crisis de la deuda externa que habían sufrido años atrás muchos de los países de la región; más que la adopción de nuevas políticas se trataba de pasar de un modelo intervencionista a uno de apertura económica que garantizara un verdadero desarrollo económico a través de la competitividad, haciendo que cada quien optara por el mejor mecanismo con el ánimo de lograr altos niveles de productividad.

La solución más apropiada en ese momento era esa; al retirarse el Estado se lograría mayor estabilidad en los mercados a través de una liberación de mercados, así: el mercado de bienes con una apertura comercial, el de capitales con una desregulación financiera y el de trabajo con una flexibilización en las relaciones salariales. En todos se desataba algo que los dejaría más libres y sin tantas normas o leyes encima, así que la única manera de sobrevivir en este mercado es haciendo méritos para ganárselo, donde, como en todo el sistema capitalista, sobrevive el más fuerte.

Viendo que el panorama de la economía latinoamericana de esos años era de déficit por la deuda, se retoma el concepto central de las finanzas públicas, que se constituye básicamente en una "redistribución de la asignación que el mercado hace de los recursos de una sociedad... las finanzas públicas estarían haciendo una asignación de recursos por fuera de la asignación que hace el mercado" (Giraldo, 2009, p. 29). Por ese intervencionismo estatal de antes de la década de los noventa se estaba impidiendo el normal flujo del mercado y de sus propias asignaciones.
Asignaciones que, simplemente y por conceptos económicos como el normal juego de oferta y demanda, garantizan un equilibrio en el mercado sin que haya más actores involucrados en él. Con el modelo anterior, al aparecer, el Estado, como institución administrativa máxima de una nación, manipula las fuerzas del mercado a su favor creando constantes desequilibrios que desencadenaron en la crisis ya mencionada.

Ahora, este nuevo modelo de mercado exige la apropiación de términos como la apertura económica, que, si bien afectaría un poco las economías nacionales, por otro lado, les exigiría un poco más de competitividad en el mundo globalizado. Esta exigencia incluía no solo la cantidad sino también la calidad con el uso, sin duda, de una mejor tecnología, es decir, estando a la vanguardia de las TIC.

Este nuevo modelo tenía muchos puntos a desarrollar en sus reformas, por ejemplo, la descentralización, más específicamente, la descentralización fiscal, con la cual, por el hecho de cambio de mecanismo, las entidades territoriales también tenían que ser partícipes. La manera de hacerlo era delegar recursos, desde el central, a los gobiernos subnacionales, pero, además de ello, delegar responsabilidades, con las que, desde su jurisdicción, pudiesen ser lo más sostenibles posible, creando competencia desde los niveles más pequeños de los territorios.

Todo lo anterior se pondrá en evidencia de manera más amplia y profunda en varios apartados: el primero empieza explicando los fundamentos teóricos de la descentralización, viendo las ideas del nuevo institucionalismo ortodoxo; luego, se centra en la explicación el Consenso de Washington; después se retoma la descentralización, haciendo alusión al concepto y a algunas consideraciones; en seguida se hace una mirada a la descentralización fiscal; y por último, se proporcionarán algunas conclusiones del balance y las perspectivas del proceso de descentralización. 
Fundamentos teóricos

de la descentralización

Al hablar de la base teórica de este tema aparece el estudio del nuevo institucionalismo ortodoxo, también llamada escuela neo institucional, que fundamenta la descentralización. Uno de sus pilares habla de:

La visión del Estado como el producto de un "contrato" entre la sociedad civil (los agentes económicos y los agentes políticos) con un sector público encargado de cumplir funciones de árbitro neutral en el proceso de producción, distribución y consumo de riqueza, del ingreso y de las oportunidades. El "principal" sería la sociedad civil que le encarga al "agente", o Estado, que asegure el funcionamiento de un conjunto de reglas (Wiesner, 1997, p. 125).

Como se puede leer, al Estado se le asigna el papel de árbitro, dando aires a lo que se conoce como descentralización, donde se deja de lado el intervencionismo estatal para dar paso al libre juego de mercado pues las regiones tienen que empezar a ser competitivas con el ánimo de conseguir recursos y ser más eficientes en cuanto a los dineros que requieren para su sostenimiento. La manera de hacerlo posible es contar con la existencia de instituciones transparentes que favorezcan las reglas de juego de la sociedad y, por ende, las del mercado para lograr así los objetivos propuestos.

Pero "hay mucho en común entre la Escuela Neoinstitucional y la Escuela de Chicago" (Wiesner, 1997, p.116). Pues,

La premisa de la Escuela de Chicago es que las personas, por lo general, tratarán de maximizar su bienestar o su utilidad y, de esta manera, compiten entre sí y generan los mercados y la competencia. Ese esfuerzo por maximizar es lo que explica la existencia de las instituciones, de los mercados, de la información, de los monopolios, de los sindicatos y de los "rent-seekers" ${ }^{3}$ " etc. (Wiesner, 1997, p.116).
Las dos concuerdan en la evidente y necesaria existencia de las instituciones en este proceso de reformas donde no sólo se habla de la responsabilidad que tiene cada territorio de lograr ser sostenible, sino de cómo hacen para lograr ese acometido; bueno allí se dan otros mercados pequeños en cuanto a la utilidad y nivel de bienestar que pueda brindar cada territorio para los residentes, y de cómo ciertas condiciones favorezcan o no su estadía en ciertos lugares, dejando estos de percibir o aumentar ciertas rentas como pueda suceder, según su nivel impositivo.

Las instituciones son importantes en este proceso pues "son consideradas como elementos del contexto estratégico, ya que imponen restricciones al comportamiento basado en el interés individual, limitando las estrategias que los actores adoptan para alcanzar sus objetivos" (Arias, 2008, p. 40); adicionalmente, el comportamiento de cada sujeto determinará el de un conjunto más amplio de individuos con intereses completamente diferentes entre ellos, pero que, gracias a unas reglas de juego, no chocarán entre sí, por el contrario, existirá progreso en los conglomerados.

Igualmente, teóricos ortodoxos, como Douglas North y Oliver Williamson, hablaban de la importancia de las instituciones en una sociedad como entidades que garantizaban el orden en ésta y sin las cuales sería complicado funcionar, pues son ellas quienes, a través de un conjunto de reglas, dan parámetros de comportamiento a los agentes de la sociedad para que el mercado cumpla sus objetivos y llegue a feliz término. En este periodo descentralizador, además de darle poder, recursos y obligaciones a los gobiernos subnacionales, también era necesario que nuevas instituciones actuaran como entes con un rol administrativo y de transparencia fiscal, "resulta, por tanto, necesario crear las adecuadas y mejorar las existentes, para evitar las perturbaciones

\footnotetext{
${ }^{3}$ Grupos de personas que logran capturar rentas.
} 
económicas y facilitar la actividad en los mercados" (Acemoglu, Johnson y Robinson, 2002, citados por Carrasco y Castaño, 2012, p. 50).

Sin embargo, en la esfera nacional no solo los movimientos económicos son importantes, sino también los políticos, y es por eso que "la segunda característica de la economía neo institucional es su reconocimiento de que en todo momento actúan, simultáneamente, los mercados económicos, de una parte, y los mercados políticos, de otra" (Wiesner, 1997, p. 119). Así, en este proceso, la aceptación de estos dos mercados y su actuar simultáneo es innegable. Si hay muchos más gobiernos locales, en tiempo de elecciones muchos aspectos se alteran, ya sea porque algunos productos son el fuerte de la región o porque se apoya a alguna fórmula política, o, simplemente, por la misma incertidumbre que se crea en aquellos momentos, pues cada propuesta tiende a reformas y a temas en específico que benefician a algunos, pero a otros no tanto. En cuanto a los orígenes y fundadores de la escuela neoinstitucional se habla del:

\section{Profesor Armend Alchian, quien, con- juntamente con Coase, podría ser con- siderado como el padre de la teoría los derechos de propiedad. Para Alchian (1965), los derechos de propiedad son en realidad las reglas de la compe- tencia. Son así también las reglas del mercado. Si fallan las reglas no hay juego (Wiesner, 1997, p. 123).}

Ésta es otra premisa de esta nueva oleada de reformas, en la cual el establecimiento de la propiedad privada es punto de partida en el nuevo proceso; establecidos esos derechos es posible acceder al mercado y participar de manera activa en él.

\section{El Consenso de Washington}

Es apenas normal que las regiones, en ocasiones, cambien de direccionamiento a través de las reformas en varios campos de la vida social. Cuando esos cambios se deben a un tema de financiamiento, es aún más serio, pues, al igual que en las pequeñas economías de hogar, es necesaria una cantidad de ingresos para poder subsistir; lo mismo pasa con los países que, cuando se endeudan demasiado y están tan metidos en la deuda, deciden refinanciar su deuda atendiendo a las condiciones que sean necesarias. Es por esto que, luego de la crisis por la deuda externa en América Latina,

La búsqueda de un modelo económico abierto, estable y liberalizado se cristalizó con la formulación del Consenso de Washington (CW) en 1989, cuyas reformas de política económica estaban basadas en una lógica de mercado caracterizada por la apertura y disciplina macroeconómica (Martínez y Soto, 2012, p. 43).

La aplicación de estas políticas neoliberales en América Latina, como se mencionó anteriormente, se debe a un problema de ingresos al cual se llegó en muchos países por las políticas proteccionistas que aparentemente darían como resultado un alto crecimiento económico de los países, pero lo que en verdad sucede es que Latinoamérica,

Comienza a endeudarse con los organismos internacionales y cuando estalla la crisis de la década de 1980 , las políticas del Consenso de Washington se convierten en el paradigma de condicionantes que los países tenían que aceptar (...) se convirtió quizá en la única opción que los países latinoamericanos tenían para salir del bache económico (Martínez y Soto, 2012, p. 61).

Estas nuevas reformas del Consenso de Washington prometían un muy buen futuro para quienes las llevaran a cabo, pues era muy diferente al modelo anterior y, además, existía un fuerte en temas macroeconómicos. El consenso contemplaba varios niveles según (Giraldo, 2009, p. 31): 
- Liberación de mercados: mercado de bienes (apertura comercial), mercado de capitales (mercado libre de divisas, apertura de capitales, desregulación financiera) y mercado laboral (flexibilización laboral)

- Políticas públicas: disciplina fiscal, focalización del gasto (subsidio a la demanda), impuestos neutrales, privatización y descentralización fiscal

- Límites al mercado: banco central independiente, sistema presupuestal jerarquizado (presupuesto público determinado por autoridad fiscal sin injerencia de órganos de representación popular u otro órgano político) y sistema judicial independiente y fuerte.

Como se observa, esa nueva reforma contemplaba muchos puntos que llevarían a un mejor funcionamiento de la economía. La primera gran apuesta era con la liberación de mercados a través de una apertura comercial en el mercado de bienes, un mercado libre de divisas en el mercado de capitales con una desregulación financiera y una flexibilización laboral. Como su nombre lo indica todo se deja al libre juego del mercado: bien para unos y mal para otros, lo cierto es que este mecanismo incentiva la competitividad en todos los sectores, ya que el proteccionismo estatal quedaba de lado y todo sería aparentemente más justo, aunque grandes y pequeños queden en el mismo plano y con opciones de competitividad diferentes.

En cuanto a las políticas públicas que planteaba dicha reforma estaban: primero una disciplina fiscal, lo cual simplemente es saber administrar muy bien los recursos públicos, es decir, que no se gaste más de lo que se tiene, medirse en los gastos, de esta manera, se podría evitar otra crisis por deuda externa.

Segundo, la focalización del gasto y subsidio a la demanda, que no es otra cosa que subsi- diar a la demanda para que ellos, teniendo los recursos, los destinen a obtener los servicios que aún les falta por sus bajos recursos económicos, de esta manera "los mercados llevarían la eficiencia en la medida en que se establece la competencia permitiendo la posibilidad de escogencia de los usuarios. De esta forma, se mercantiliza la provisión de los bienes públicos" (Giraldo, 2009, p. 34).

Tercero, los impuestos neutrales, donde se plantea que "el principio de la neutralidad tributaria significa que el sistema impositivo debe producir distorsiones mínimas respecto al papel que cumple el mercado en la asignación de los factores de producción" (Giraldo, 2009, p. 35); por lo cual, lo más viable son impuestos regresivos, universales y con tarifa uniforme, como el IVA, que no altera los pecios relativos.

Cuarto, la privatización: "la provisión de bienes y servicios estatales puede ser asumida por el sector privado y cuando ello es posible la participación del Estado en dicha provisión significará una intervención excesiva" (Giraldo, 2009, p. 35), en el sentido que estaría obstruyendo la libre competencia y el libre juego de mercado que se supone lleva a la eficiencia en su óptimo (punto de equilibrio).

Finalmente, se encuentra el quinto punto: la descentralización fiscal, que buscaba darle la oportunidad a los territorios de decidir sobre su propia carga impositiva, y de esta manera, tratar de ser sostenibles, ya que serían ellos mismos los encargados de solucionar problemas sociales y de educación. Además, este tipo de reforma,

También puede ser vista desde la óptica del mercado, en la medida en que se la concibe como un mecanismo para introducir competencia de mercado entre las regiones y localidades, y permitir una relación más cercana entre la institución que provee el servicio y el usuario (Banco Mundial, 1997, pp.125 y $136 \mathrm{ss}$, citado por Giraldo, 2009, p. 36). 
Asimismo, "uno de los componentes centrales de la reforma del Estado en Latinoamérica es la descentralización. Se le considera una pieza fundamental en las reformas económicas e institucionales, las cuales, como se dijo, están basadas en la preeminencia del mercado" (Giraldo, 2009, p. 137). Era pues necesario que el gobierno central delegara responsabilidades a los territorios, para que desde allí se pudiesen llevar los nuevos lineamientos a todos los rincones de los países. Pero no sólo eso, también el hecho de que las personas, como en un mercado cualquiera, puedan, por ejemplo, elegir el lugar dónde desean vivir según las condiciones que ofrece cada lugar (mejores servicios y cobren menos impuestos), pues éste también es un caso de competencia y elección del consumidor.

Pero el Consenso también establecía lo que Giraldo denominó los límites al mercado, que constituyó, no en otra cosa que unas instituciones de control, pues, como se sabe, son ellas las que hacen cumplir ciertas reglas para que todo fluya en normal funcionamiento. Esas instituciones eran: primero, un banco central independiente, una institución distinta al mercado y al gobierno que manejara variables trascendentales, como la tasa de cambio y la inflación, y a ellas unidas muchas más para garantizar una estabilidad monetaria; un sistema presupuestal jerarquizado que garantizara prioridad al servicio, contribuyendo con la integridad física y emocional de las personas; y por último, un sistema judicial independiente para que haya transparencia en los sistemas judiciales.

\section{La descentralización: el concepto}

La descentralización es, en términos sencillos, distribuir recursos y responsabilidades a todas las entidades que componen el central, así, el central se quitará un peso de encima y dará más autonomía a todos sus estados para que sean autosuficientes en todos los aspectos que implica el sustento de un gobierno local.

La descentralización en América Latina fue un proceso que se dio poco a poco, desde la década de los 80, como parte de las reformas del Consenso de Washington. Con éste se buscó que también se aplicara el libre mercado en las regiones de los gobiernos subnacionales, con el propósito de mejorar la economía de las naciones, pues cada región buscaría, a su manera, un crecimiento económico que se reflejaría en el nacional a corto plazo. El marco social en el que se fue dando este paso y como

Uno de los principales hechos sociales
que precedieron y dieron marco a la
descentralización fue la notable ur-
banización que ocurrió entre los años
sesenta y ochenta del siglo pasado.
En ese periodo, el 90\% del crecimien-
to demográfico de América Latina se
presentó en las ciudades. La creciente
demanda de servicios básicos urba-
nos y la intensa migración a las ciu-
dades provocaron grandes demandas
locales que desafiaron la configura-
ción centralizada tradicional (Pinilla,
Jiménez, Montero, 2015, p. 134).

Este fenómeno observado en el continente se dio, por ejemplo, con los pasados aires de industrialización que se presentaron en algunos países, donde, en ese momento, el gobierno intervino arduamente para lograr que las economías nacionales crecieran; aquella industrialización, en su mayoría, ocurrió en los centros urbanos, por lo que allí representaba para las gentes una oportunidad para conseguir empleo y hacer crecer las pequeñas economías del hogar. Esto posibilitó más aún la descentralización pues existían urbes bastante grandes que darían buenos aires al naciente proceso, capaces de hacer una buena gestión fiscal.

Se dice también que "la descentralización contribuiría a la competitividad en tres aspectos: (a) desconcentrando las actividades 
productivas; (b) aumentando la eficiencia en la prestación de los servicios, y (c) aumentando la participación local en los ingresos fiscales" (Finot, 2001, p. 18). Sin embargo, muchos veían la descentralización con mucha controversia, pues se dice que:

La descentralización tenía doble carácter, de un lado estaban quienes promovían el ajuste y la reforma económica, de otro, era un espacio de negociación con la clase política para la introducción de los programas de ajuste y la readecuación de la intervención estatal a la apertura económica (Giraldo, Salama, González y Mora, 1998, p. 135).

No obstante, como en toda reforma política, se trataba que las nuevas reformas fueren deslumbrantes para que todo el proceso se llevara con más agilidad y, así, se lograra mayor aceptación para luego encargarse de las negociaciones políticas a las que hubiere caso. En fin, esta parte del proceso, además de seguir un modelo de descentralización, también tenía muchos intereses políticos, como en cualquier manejo de finanzas o recursos; con esto se puede poner en evidencia que sí existe una diferencia entre las finanzas privadas y las públicas, ya que "mientras que en las privadas las decisiones dependen de la rentabilidad, riesgo y liquidez de un activo financiero, en las públicas las decisiones son políticas" (Giraldo, 2009, p. 22). Entonces,

El impulso descentralizador fue entonces producto de una conjunción de intereses: los de quienes proponían recurrir al mercado para superar el déficit fiscal, los de nuevos gestores públicos que aspiraban a reducir los costos de transacción y hacer más eficiente la prestación de servicios públicos, y los de una generación de actores sociales y políticos con nuevas concepciones de la democracia (Nickson, 1995; Fleury, 1999; Assies, 2003; citados por Pinilla et al., 2015, p. 135).
Sin embargo, según Mayoral y Uribe (2010). "las administraciones tributarias de los países de América Latina han mostrado un desigual desempeño en la efectividad de sus políticas tributarias" (p. 85), pues cada región actuaba según su entorno económico, tamaño, población, niveles de producción, en fin, cada uno adoptó las políticas de manera diferente, no obstante, éstas concluyen en un mismo punto: la descentralización. En este traspaso al neoliberalismo,

Para imponer el "fundamentalismo de mercado" se traspasa la propiedad colectiva, bajo su forma estatal, masivamente a las redes empresariales trasnacionales, y lo que queda de la administración pública se somete a la lógica del mercado, principalmente mediante la aplicación del principio de la "libre competencia" entre empresas de cualquier naturaleza jurídica (Restrepo, 2008, p. 7).

Por lo que según Giraldo (2009), "si la descentralización se lleva hasta sus últimas consecuencias, se llega a la privatización" (p.36); lo cual, si se revisa bien, es otro de los fines de las políticas. La libre competencia será la solución para los problemas de desigualdad económica, aparentemente.

En "la óptica de quienes promovían la reforma, la descentralización era una oportunidad para trasladar responsabilidades fiscales a los gobiernos locales y de esa forma resolver la crisis fiscal" (Giraldo et al., 1998, p.135), pues, de una u otra manara, delegarían a las localidades, no sólo transferencias, sino también obligaciones para que el central se descansara un poco y pudiera ocuparse con más recursos de la deuda externa que tanto acongojaba a las regiones por esos años. Además de eso, y para mejorar el marco fiscal de las naciones, en muchas de ellas se tendió a aumentar el recaudo de impuestos, lo que mostraba la buena adopción de las políticas, sin embrago, en América Latina, 
La prioridad en la distribución del gasto público no estriba en la búsqueda de satisfacer las necesidades de los ciudadanos, o en garantizar un sistema integral de derechos sociales y económicos; la prioridad descansa en hacer sostenible el pago de la deuda pública (...) (Giraldo, 2009, p. 13).

Era razonable que la preocupación principal de las naciones fuera el pago de la deuda, y fue por ese motivo que accedieron a la implementación de estas nuevas reformas. De esta forma, "la descentralización política se llevó a cabo mediante grandes y variadas reformas legales, como la adopción de nuevas constituciones o reformando las existentes" (Pinilla et al., 2015, p. 136), donde, por ejemplo, establecieron las categorías de los municipios, estados, gobernaciones; el nombre y destino de las transferencias que se harían; si allí se les indicaría qué recursos serían de libre destinación y cuáles no. Así, poco a poco se fueron reformando las leyes para irlas adecuando según los cambios y direccionamiento del proceso. Pero, igual, las transferencias se convirtieron en el principal elemento de la descentralización pues este rubro lo tendrían sin falta los locales, aunque en algunos países iba acompañado de un factor: que no eran de libre disponibilidad, lo que significaba algunas condiciones, como cierto porcentaje para salud y obras sociales.

En algunos escenarios políticos se llegó al punto "donde la política subnacional cobra creciente importancia frente a los acontecimientos nacionales" (Arévalo y Angarita, 2011, p.289), pues cabe decir que se volvió posible que un conglomerado de locales llegaran a ser más fuertes, incluso, que el gobierno nacional, convirtiéndose en organizaciones fuertes que pueden pelear por el cambio de algunos reglamentos que favorezcan a la mayoría; "sin embargo, no siempre se han tenido los resultados esperados, pues diversos estudios muestran que aún con el proceso de descentralización fiscal en marcha, se mantienen las desigualdades en el territorio de los países latinoamericanos" (Flores, 2012, p. 8).

Descentralización fiscal. Ya delegadas las funciones y responsabilidades era necesario también dar transferencias para el sostenimiento de aquellos gobiernos y dejar aspectos libres para que ellos tuvieran la oportunidad de algunos recaudos para su desarrollo, "uno de los principales desaciertos de este periodo fue dar prioridad 'a cualquier precio' al reparto de recursos sin contraprestación, en vez de alentar el proceso con incentivos adecuados" (Pinilla et al., 2015, p. 142). Lo anterior provocó, en algunos territorios, una cómoda subsistencia con los recursos que giraba el central sin esforzarse un poco, o nada, por gestionar más fondos para su propio desarrollo local; esto frenó mucho el crecimiento que, en teoría, se esperaba vendría con estas políticas.

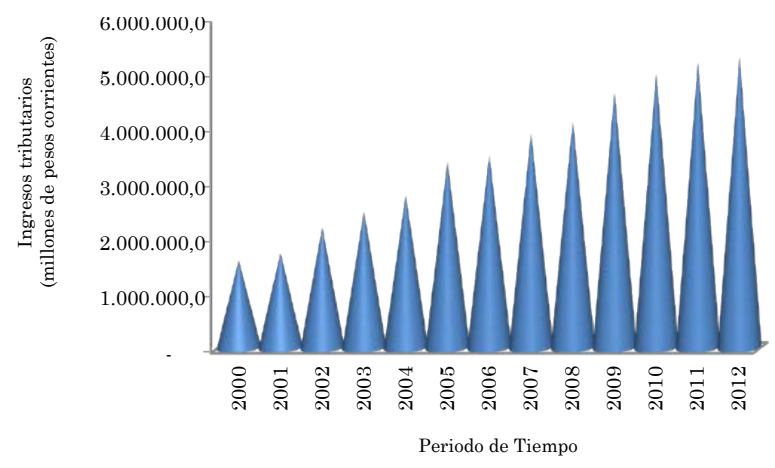

Gráfico 1. Ingresos Tributarios de los Gobiernos Subnacionales en Colombia (2000-2012).

Fuente: elaboración propia con base en DNP-Ejecuciones Presupuestales Departamentales 2000-2012.

Según el gráfico 1 se observa que los gobiernos subnacionales en Colombia, en el transcurso de 12 años, han aumentado considerablemente sus ingresos tributarios en pesos corrientes, por lo que aparentemente ha mejorado el fisco de las regiones con grandes oportunidades para hacer mayores inversiones sociales e ir reduciendo las deudas que existan en el momento, pero en esos recursos también se incluían los recursos que giraba el central. Entonces, 
El acento en las transferencias nacionales desincentivó el esfuerzo fiscal propio (Wiesner, 1992). La mayoría de las entidades locales se volvió sumamente dependiente de las transferencias que se repartían en forma automática y en creciente cantidad, sin ninguna condición. La descentralización solo tiene sentido si los ingresos locales crecen a un ritmo similar al del ingreso nacional (Wiesner, 2003, citado por Pinilla et al., 2015, p. 142).

Adicionalmente, los gastos locales aumentaban, pero el esfuerzo fiscal propio no lo hacía de la misma manera; era todo lo contrario a lo que prometía el proceso. Esos gastos aumentaban gracias al endeudamiento pues "los empréstitos pueden desempeñar una función importante en el financiamiento del nivel subnacional, en especial cuando se trata de financiar grandes obras" (Burki, Perry y Dillinger, 1999, p. 31).

Así, empezó a visualizarse una pugna entre el central y las regiones pues "la descentralización fue abiertamente asimétrica con respecto a las responsabilidades; de manera que el interés estaba en descentralizar los gastos mas no los impuestos porque estos debían quedar en el gobierno nacional, quien era el principal responsable del pago de la deuda externa" (Giraldo, 2009, p. 145). De manera que "si existe 'dependencia fiscal' es porque hay centralización de la fiscalidad y si se quiere aumentar la autonomía fiscal local se impone una reforma al sistema tributario que equilibre la disponibilidad de recursos entre niveles de gobierno" (Restrepo, 2008, p. 17).

Lo claro es que, aunque aumentaban en algunos lugares los ingresos, lo era en su mayoría gracias a las transferencias, sin embargo, cuando se habla de que una región es sostenible lo que en verdad debe suceder es que se reduzcan las transferen- cias, pero, a la vez, se le de más oportunidad de recaudo, pues los gravámenes de mayor importancia llegan al central, por lo que es apenas normal que "los niveles locales querían recibir más recursos pero no nuevas responsabilidades, y el nivel central buscaba desprenderse de competencias sin darles mayor autonomía tributaria” (Aghón, 1999, citado por Pinilla et al., 2015 , p. 142). Ahora entra aquí un nuevo punto a discutir, y es el de la desigualdad entre el central y las regiones. No obstante, el problema no es el fin como tal, sino la forma en que se pretende lograr pues,

Sin duda, la descentralización fue un pilar fundamental de la modernización del Estado que se complementó con otras reformas (Aghón, 1997), y permitiría lograr varios objetivos: eficiencia, mayor equidad, menor corrupción y equilibrio fiscal. En suma, el intenso proceso de urbanización, la ineficiencia del modelo centralista, las crisis fiscales y la liberalización determinaron o promovieron la descentralización en América Latina, y esta era una condición para profundizar la democracia (explicación política) y parte fundamental de un nuevo paradigma (explicación económico-estructural e ideológica) (Pinilla et al., 2015, p. 138).

Según historiadores "en un primer momento, la descentralización fue ante todo un proceso político y de reforma estructural, impulsado por la idea de que un sistema de gobiernos locales era económica y políticamente más provechoso" (Pinilla et al., 2015, p. 141), no solo para ellos, sino para la economía nacional. Sin embargo,

Los procesos de descentralización no tienen una sola potencialidad, ni un solo propósito político. Sus características son el resultado, en cada país, de la pugna entre las principales fuerzas que han intervenido en el rediseño del Estado en las últimas décadas (Restrepo, 2008, p. 2). 
Además, no todos los países latinoamericanos reaccionaron de la misma forma, ya que cada uno de ellos es diferente, política, social y económicamente hablando. Lo que sí fue cierto es que la mayoría de los países asumió esas nuevas funciones sin haber mejorado las estructuras organizativas, por lo que,

Esta manera de llevar a cabo la descentralización suscitó varios inconvenientes, el principal de esos graves problemas fiscales en Argentina, Bolivia, Brasil, Colombia, Ecuador, México y Venezuela. A medida que el proceso avanzaba era más evidente que se había sobrestimado como mecanismo de ajuste fiscal. La experiencia confirmó que la transferencia de competencias de gasto a las entidades locales no era tan beneficiosa para las cuentas públicas como se esperaba, debido en parte a que, por falta de claridad, las transferencias terminaron provocando cuantiosos déficits subnacionales y rescates periódicos a los gobiernos locales más endeudados. Las cuentas fiscales empeoraron en los años noventa y a comienzos de siglo, y el gasto público como porcentaje del PIB creció en forma continua (Pinilla et al., 2015, p. 144).

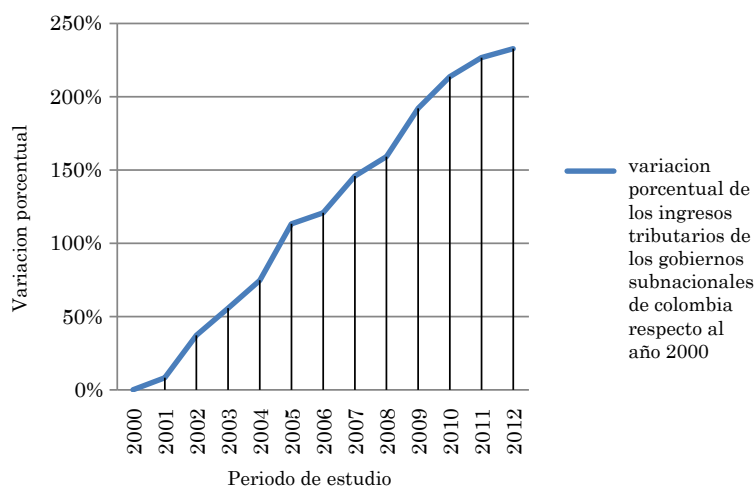

Gráfico 2. Ingresos Tributarios de los Gobiernos Subnacionales en Colombia: Porcentaje de crecimiento respecto al año inicial (2000-2012).

Fuente: elaboracion propia con base en DNP-Ejecuciones Presupuestales Departamentales 2000-2012.
Pero no todo el proceso fue negativo. Algunos municipios aprovecharon esa situación para modernizar sus sistemas tributarios, hacer obras públicas e incentivar la participación ciudadana, lo que garantizó que fueran, de por sí, más exitosos que los demás, aprovechando sus ventajas comparativas, lo que se refleja en el gráfico 2 , donde se muestra que en 12 años aumentó el recaudo de ingresos tributarios en un $233 \%$ con respecto al año inicial (2000), situación que resalta por el esfuerzo fiscal de algunos locales que llevaron las cifras generales al tope y demostraron que sí puede funcionar el modelo.

Según Giraldo (2009), en América Latina se dieron dos tipos específicos de descentralización: una fue política y fiscal, que consistió en trasladar competencias y recursos a los gobiernos locales para su fortalecimiento; y el otro de tipo fue administrativo y fiscal, donde solo se trasladaron recursos, pero no competencias. Así, esta última estaba salida de base pues no era razonable mandar transferencias sin destinación alguna, por lo que se podía, en ese caso, malbaratar los dineros públicos.

\section{Conclusiones}

La descentralización en América latina, que viene rodando en el continente desde la década de los 80, es consecuencia de la crisis de la deuda externa que afectó a la mayoría de los países latinoamericanos, pues al agrandar la deuda con los organismos internacionales, estos quedarían a disposición de aquellos, por lo que la única opción para el refinanciamiento de los países debía ser la aplicación de las reformas del Consenso de Washington para lograr un rendimiento económico mucho mayor y garantizar mejores indicadores macroeconómicos que sacarían a la región por el camino de la prosperidad.

Estos indicios de descentralización tenían como base las nuevas ideas del institucionalismo ortodoxo o la escuela neoinstitucional, 
que daba nuevos aires en cuanto al papel del Estado y de las instituciones en la organización económica de una sociedad. En cuanto al Estado, lo ponen solamente como el garante de un conjunto de reglas, en un lugar donde hay un principal, que es el pueblo en general, quien delega a éste para que asegure el cumplimiento de una serie de reglas dentro de todo el proceso de producción, distribución y consumo del ciclo normal de las economías. Las instituciones cumplen un papel primordial en este mecanismo, pues sin ellos sería complicado funcionar, ya que son ellas quienes, a través de un conjunto de reglas, dan parámetros de funcionamiento en una sociedad; otro aspecto importante de esta corriente de pensamiento es el establecimiento de los derechos de propiedad, pues así se hace más competitivo el sistema.

La Escuela de Chicago dice que las personas siempre tratarán de maximizar su bienestar o su utilidad, y para esto compiten entre sí, generando los mercados, por lo que ello explica la existencia de las instituciones, información, monopolios y demás sujetos que participan; ahí se ve el origen de las nuevas reformas descentralizadoras, donde se deja todo al libre juego de mercado, incluso, las entidades territoriales, para que busquen ser eficientes ellos mismos. También las personas lo hacen, pues existiendo una gran cantidad de territorios con diferentes particularidades en cada uno, como en un mercado, cada uno decidirá dónde vivir según muchos aspectos: la conveniencia, la localización, el costo, y, también, las tarifas impositivas de cada uno, que, si bien tienen normas específicas en cuanto a máximos y mínimos, se podrá decidir dentro del rango de ese intervalo, según las condiciones socioeconómicas de los territorios.

Al pasar de un sistema de intervención estatal a uno de libre juego de mercado, donde poco a poco se irían eliminando barreras, el sistema se supondría más competitivo y llegaría a alcanzar la eficiencia económica.
A dichas reformas se les denominó Consenso de Washington, el cual tenía varios puntos que se pueden agrupar en tres niveles, según Giraldo (2009). Estos tres niveles incluyen: uno, liberación de mercados; dos, políticas públicas; y tres, límites al mercado. Esta visión es muy interesante pues, primero, y como se ha venido explicando, hay un libre marcado, pero se incluyen políticas públicas que, si bien no deben afectar el libre curso del mercado, serán muy favorables a la hora de mejorar condiciones $y$, como segunda medida, se establece que hay límites en ese mercado, estableciendo ciertas instituciones independientes que participarán como árbitros para que las situaciones no se salgan de las manos.

Este proceso empezó delegando responsabilidades y transferencias a los territorios con el fin de que empezaran ellos mismos a hacer cargo de sus necesidades y empezaran a buscar nuevos ingresos a través de nuevos impuestos, pero se observa que el esfuerzo fiscal de la mayoría de ellos no era significativo y para financiar sus obas y servicios accedieron al endeudamiento, lo que no le pareció muy agradable al central pues tenía que intervenir.

En varios de los países de la región hubo problemas fiscales, ya que ejecutaron esas nuevas reformas sobre una estructura organizativa antigua y obsoleta que no permitió el ritmo que se necesitaba para cumplir los objetivos de la política descentralizadora, tal es el caso de Argentina, Bolivia, Brasil, Colombia, Ecuador, México y Venezuela.

\section{Referencias}

Arévalo, J. y Angarita, G. (2011). Descentralización y equilibrio de poder en América Latina. Revista Economía Institucional, 14(27), pp. 289-296. Recuperado de: https://www.economiainstitucional.com/pdf/No.\%2027\%20pdf/ jarevalo.pdf 
Arias, A. (2008). El neoinstitucionalismo y sus aportes a la teoría de la organización. Revista Gestión \& Región, (6), pp. 31-64. Recuperado de: file:///C:/Users/ Jose/Downloads/902-853-1-PB\%20(1). pdf

Burki, S., Perry, G. y Dillinger, W. (1999). Más allá del centro: la descentralización del Estado. Estudios del Banco Mundial sobre América Latina y el Caribe. Washington D.C.: Banco Mundial. Recuperado de: http://documentos.bancomundial. org/curated/es/390121468045234553/ pdf/196360PAPER0Beyond1Spanish. pdf

Carrasco, I. y Castaño, M. S. (2012). La Nueva Economía Institucional. Nuevas Corrientes de Pensamiento Económico ICE, (865), pp. 43-53. Recuperado de: http://www.revistasice.com/CachePDF/ ICE_865_43-54_5BCB3F74AF28A44 ODCF8EF9FFFBA0496.pdf

DNP. (s.f.). Ejecuciones Presupuestales Departamentales 2000-2012. Recuperado de: https://www.dnp.gov.co/programas/ desarrollo-territorial/Paginas/ejecuciones-presupuestales.aspx

Flores, A. (2012). Avances de la descentralizacion fiscal en países de America Latina. Evaluación y propuestas para el caso de Perú. Red Latinoamericana sobre Deuda, Desarrollo y Derechos. Recuperado de: http://www.justiciafiscal. org/wp-content/uploads/2012/11/AVANCES-DESCENTRALIZACI\%C3\%93NFISCAL-EN-AM\%C3\%89RICA-LATINA-1.pdf

Finot, I. (2001). Descentralización en América Latina: teoría y práctica. CEPAL. SERIE Gestión Pública, (12). Santiago de Chile: CEPAL. Recuperado de: http:// repositorio.cepal.org/bitstream/handle/11362/7261/1/S01030319_es.pdf

Giraldo, C. (2009). Finanzas públicas en América Latina. La economía política. Bogotá: Ediciones desde abajo.
Giraldo, C., Salama, P., González, J. y Mora, O. (1998). Crisis fiscal y financiera en América Latina. Bogotá, D:C.: Tercer mundo editores.

Martínez, R. y Soto, E. (2012). El Consenso de Washington: la instauración de las políticas neoliberales en América Latina. Política y Cultura, (57), pp. 35-64. Recuperado de: http://www.scielo.org. $\mathrm{mx} / \mathrm{pdf} /$ polcul/n37/n37a3.pdf

Mayoral, F. y Uribe, C. (2010). Determinantes económicos e institucionales del esfuerzo fiscal en América Latina. Investigación Económica, LXIX(273), pp. 85-113. Recuperado de: http://www. redalyc.org/pdf/601/60114744003.pdf

Pinilla, D., Jiménez, J. y Montero, R. (2015). La descentralización fiscal en América Latina. Balance de un proceso. Revista Economía Institucional, 17(33), pp. 133-160. Recuperado de: http://www. redalyc.org/pdf/419/41943054006.pdf

Restrepo, D. (2008). Descentralización para la equidad. Economía, Sociedad y Territorio, 12(40), pp. 793-821. Recuperado de: http://www.scielo.org. $\mathrm{mx} /$ scielo.php?script=sci_arttext\&pid $=$ S1405-84212012000300009

Wiesner, E. (1992) El diseño de un sistema de evaluaciones de resultados: principios y opciones, control y evaluaciones de la gestión pública. Los desafíos de la nueva Constitución, Bogotá, D:C.: DNP.

Wiesner, E. (1997). La efectividad de las políticas públicas en Colombia- un análisis neoinstitucional. Primera edición. Bogotá, D:C.: Tercer mundo editores.

Wiesner, E. (2003). Descentralización y equidad en América Latina: Enlaces Institucionales y de Política. Archivos de Economía, documento 227. Recuperado de: https://colaboracion.dnp.gov. co/CDT/Estudios\%20Econmicos/227. pdf 